\title{
L-GLUTAMINE ERADICATES HELICOBACTER PYLORI GASTRITIS: A NOVEL CASE REPORT
}

\author{
BALAJI 0*, AMITA P
}

Department of Pharmacology, KMC, Manipal, Karnataka, India. Email: puntermmc@gmail.com

Received: 25 March 2017, Revised and Accepted: 07 July 2017

\begin{abstract}
Helicobacter pylori is the most common infection causing gastrointestinal diseases in the developing countries. It causes oxidative damage to gastric mucosal cells thereby altering the epithelial proliferation of these cells. With proton pump inhibitors and antibiotics being the mainstay in the management of symptoms, preclinical and clinical research is making inroads with novel therapeutic innovations to target the bacterium with the help of antioxidants. Hence, we report the first case of the treatment and eradication of $H$. pylori using L-glutamine, a sports medicine supplement with high antioxidant potential
\end{abstract}

Keywords: Proton pump inhibitors, L-glutamine, Free radicals, Gastric reflux disease.

(C) 2017 The Authors. Published by Innovare Academic Sciences Pvt Ltd. This is an open access article under the CC BY license (http://creativecommons. org/licenses/by/4. 0/) DOI: http://dx.doi.org/10.22159/ajpcr.2017.v10i10.18704

\section{INTRODUCTION}

Helicobacter pylori is one of the most dreaded bacterial infection affecting more than $50 \%$ population globally. It causes many gastrointestinal diseases ranging from peptic ulcers, gastric ulcers, gastric carcinoma, and lymphomas. Various treatment regimens are used to treat this infection with proton pump inhibitors (PPI), antibiotics being the main stay in curing the disease. However, despite available drugs to treat the infections, there is increased prevalence of the infection in developing nations [1]. Hence, we report a case of 45-year-old male, diagnosed of $H$. pylori positive gastritis with reflux disease treated with L-glutamine in a tertiary care hospital in India.

\section{CASE REPORT}

Informed consent was taken from the patient. A 45-year-old male patient, business man by occupation, came with complaints of on and off abdominal pain, dyspepsia, bloating sensation in stomach after eating, heart burn, and epigastric tenderness after food intake. He had no symptoms of angina, and his vital examination was normal. Another system examination was also normal. 24-hrs monitoring of gastric $\mathrm{PH}$ was diagnostic of gastric esophageal reflux disease along with gastritis. Ultrasound abdomen was normal. Upper gastrointestinal endoscopy was suggestive of gastritis without any ulcer formation. Then, in view of $H$. pylori, infection patient was taken for biopsy and rapid urease test for $H$. pylori came positive. The patient was immediately started with triple drug therapy consisting of lansoprazole, amoxicillin, and clarithromycin for 14 days twice daily. There was no improvement in symptoms, and the whole treatment was again repeated for a course of 14 days. After 2 courses of triple drug therapy, the patient was taken for second endoscopic biopsy to know the status of $H$. pylori infection. The patient was again positive for $H$. pylori. Then, the patient was started with oral L-glutamine supplement $1000 \mathrm{mg}$ capsules twice daily for a period of 30 days. At the end of 30 days' patient's symptoms improved and a repeat biopsy of gastric tissue came negative for $H$. pylori. Hence, forth patient was advised diet changes and not to skip meals. He was also advised physical exercise and to avoid nonsteroidal antiinflammatory drugs and other drugs causing gastritis. On follow-up at 6 months repeat biopsy again showed eradication of $H$. pylori infection and patient was completely cured and H. pylori eradicated.

\section{DISCUSSION}

H. pylori, affecting almost half of the population globally is highly prevalent in developing countries with an incidence of $90 \%$ compared to developed countries with $40 \%$ incidence [1]. It affects all ages and both men and women equally causing myriad of gastrointestinal problems ranging from peptic ulcer disease to gastric carcinomas. The effective treatment of $H$. pylori infection remains a challenge as the entire treatment depends on the availability of diagnostic procedures, choice of one detection method over other, cost of endoscopic procedures and also taking into consideration the age of the patient. Triple drug therapy remains the standard treatment measure offering good cure rates [1]. Various newer treatment options such as quadruple therapy, sequential therapy, and concomitant therapy have improved the cure rates in developing as well developed countries to a substantial amount. Rapid urease test of endoscopic stomach biopsies remains the most widely used method as it is inexpensive, rapid and cost effective with high specificity and sensitivity [1]. Triple therapy consists of lansoprazole $30 \mathrm{mg}$, clarithromycin $500 \mathrm{mg}$, and amoxicillin $1 \mathrm{~g}$ twice daily for 14 days. In the case of allergy to penicillin's, metronidazole is used [1]. A meta-analysis revealed triple therapy had 6-10\% high eradication rates when compared to PPI when used alone [2]. Lactoferrin in combination with triple therapy is used to reduce the side effect of the drugs. In the case of high resistance to clarithromycin, quadruple therapy consisting of PPI, bismuth subsalicylate ( $525 \mathrm{mg} \times 4$ daily), metronidazole (250 mg $\times 4$ daily), and tetracycline $(500 \mathrm{mg}, \times 4$ daily), for $10-14 \mathrm{~d}$ is used [3]. Sequential therapy involves the use of PPI plus amoxicillin for first 5 days followed by metronidazole/clarithromycin for next 5 days. A meta-analysis showed sequential therapy was better than 7-day triple drug therapy, but there was no significant difference when compared with 14-day triple therapy [4]. In the case of resistance of clarithromycin more than 20\%, concomitant therapy consisting of three antibiotics (metronidazole, clarithromycin, and amoxicillin) and a PPI for 10 days is used and is found to be effective and well tolerated compared to triple therapy [5].

Oxidative stress has been implicated in the pathogenesis of $H$. pylori infections and increased oxidative damage by $H$. pylori is responsible for epithelial injury, altered epithelial proliferation, and increased apoptosis [6]. Furthermore, it has been found out that there is an accumulation of ammonia in the gastric tissues which leads to gastric mucosal damage [7]. H. pylori has specificity for gastric epithelium and is enhanced by oxidative damage [8]. L-glutamine commonly used in sports medicine for muscle recovery is a non-essential amino acid and has gained medical importance because of its antioxidant properties [9]. The antioxidant properties of L -glutamine have been claimed to be useful in the treatment of peptic ulcer disease in animal 
studies as well in very few human studies. Only a few animal studies have been conducted so far to investigate the role L-glutamine in the treatment of $H$. pylori infections and it was found to be positive, yet human trials have not been done in large scale [10]. As evidence says, glutamine helps in reducing the accumulation of ammonia in gastric tissue and cells as well it helps in reducing the oxidative free radicals in gastric tissue thereby controlling the changes induced by $H$. pylori infection in gastric epithelial cells [9]. Our case is the first one to be reported so far in world literature where L-glutamine has been used in the treatment of gastritis with reflux disease in a male patient after failure in eradicating helicobacter infection by conventional methods. In our case, the patient was given a 14-day course of triple drug therapy twice in a month and after the failure of the treatment was started on L-glutamine supplementation for 30 days. This novel treatment with L-glutamine resulted in complete eradication of the bacterial infection with negative rapid urease test of the biopsy samples. The patient was followed up for 6 months, and he was normal, and there was no recurrence of gastric symptoms. There were no adverse effects noted during the treatment and patient was very much agile and active.

\section{CONCLUSION}

Further clinical trials can be done using L-glutamine in $H$. pylori infected patients and efficacy and safety can be evaluated in comparison with conventional treatment methods. This was the first case report in the world, on using L-glutamine in the treatment of gastritis with reflux disease due to $H$. pylori. Hence, antioxidative properties of L-glutamine can be of great help in revolutionizing the management of $H$. pylori infections.

\section{REFERENCES}

1. Garza-González E, Perez-Perez GI, Maldonado-Garza HJ, Bosques-Padilla FJ. A review of Helicobacter pylori diagnosis, treatment, and methods to detect eradication. World J Gastroenterol 2014;20(6):1438-49.

2. Loyd RA, McClellan DA. Update on the evaluation and management of functional dyspepsia. Am Fam Physician 2011;83(5):547-52.

3. Malfertheiner P, Megraud F, O'Morain CA, Atherton J, Axon AT, Bazzoli F, et al. Management of Helicobacter pylori infection - The Maastricht IV/Florence Consensus Report. Gut 2012;61(5):646-64.

4. Gatta L, Vakil N, Leandro G, Di Mario F, Vaira D. Sequential therapy or triple therapy for Helicobacter pylori infection: Systematic review and meta-analysis of randomized controlled trials in adults and children. Am J Gastroenterol 2009;104(12):3069-79.

5. Stenström B, Mendis A, Marshall B. Helicobacter pylori - The latest in diagnosis and treatment. Aust Fam Physician 2008;37(8):608-12.

6. Ding SZ, Minohara Y, Fan XJ, Wang J, Reyes VE, Patel J, et al. Helicobacter pylori infection induces oxidative stress and programmed cell death in human gastric epithelial cells. Infect Immun 2007;75(8):4030-9.

7. Lytton SD, Fischer W, Nagel W, Haas R, Beck FX. Production of ammonium by Helicobacter pylori mediates occludin processing and disruption of tight junctions in Caco-2 cells. Microbiology 2005; $151: 3267-76$

8. Ashwini P, Sumana MN, Shilpa U, Mamatha P, Manasa P, Dhananjaya BL, et al. A review on Helicobacter pylori: Its biology, complications and management. Int J Pharm Pharm Sci 2011;7 Suppl 1:14-20

9. Heyland DK, Elke G, Cook D, Berger MM, Wischmeyer PE, Albert M, et al. Glutamine and antioxidants in the critically ill patient: A post hoc analysis of a large-scale randomized trial. JPEN J Parenter Enteral Nutr 2015;39(4):401-9.

10. Amagase K, Nakamura E, Endo T, Hayashi S, Hasumura M, Uneyama H, et al. New frontiers in gut nutrient sensor research: Prophylactic effect of glutamine against Helicobacter pylori-induced gastric diseases in mongolian gerbils. J Pharmacol Sci 2010;112(1):25-32. 